\title{
Composto de marketing da carne de siri pescado com gaiolas no litoral do Paraná
}

O elevado esforço de pesca que praticado no litoral paranaense conjuminou que os estoques naturais de peixes e camarões não conseguiram se reproduzir a mesma velocidade das inovações tecnológicas, fato que obrigou muitas famílias de pescadores a buscarem alternativas de renda. Entre as novas atividades surgiu a pesca do siri com gaiolas, atualmente praticada por mais de 150 famílias que comercializam a carne do crustáceo junto a restaurantes especializados em frutos do mar. Apesar do crescimento da atividade no contexto de geração de renda regional, não foram encontrados estudos sobre o sistema de comércio deste produto. Neste contexto, visando subsidiar o estabelecimento de ações de marketing para o segmento comercial varejista da cadeia produtiva do siri pescado com gaiolas, este estudo investigou a influência do composto de marketing: preço, praça, promoção e produto, no comportamento de compra do consumidor. Foi realizado entre setembro a novembro de 2015, estudo exploratório-descritivo junto a 177 consumidores. Identificou-se que o consumo médio era de 2,69 vezes ao ano, sendo que as principais iguarias feitas da carne de siri eram a casquinha de siri frita $(n=87 \%)$, seguido pelo bolinho da carne de siri $(n=31 \%)$ e posteriormente risoto, hambúrguer e pizza (13\%). Concluiu-se que os principais produtos que a substituem a carne de siri de gaiola quando a mesma não é encontrada é o peixe e camarão, e em menor proporção carnes e aves. O preço, a aparência do produto, o cheiro, e qualidade do atendimento no momento da compra, são os fatores do composto de marketing que geram os maiores índices de insatisfação juntos aos consumidores.

Palavras-chave: Comércio de Pescados; Crustáceos; Litoral do Paraná; Siri de Gaiola.

\section{Marketing mix of shell crab meat caught with cages in Paraná coast}

The high fishing effort practiced in Paraná Coast matches that natural stocks of fish and shrimp could not reproduce in the same speed of technological innovations, a fact that has forced many fishermen's families to seek alternative sources of income. Among the new activities appeared the production of shell crab in cages, nowadays practiced by more than 150 families who sell the meat of this crustacean in restaurants specialized in seafood. Despite the growth of this activity in the context of regional income generation, there are no studies about the trading system of this product. In this context, in order to support the establishment of marketing actions for the retail trade segment of the shell crab supply chain that are fished in cages, this study investigated the influence of the marketing mix: price, place, promotion and product, in consumer buying behavior. It was conducted from September to November 2015, an exploratory and descriptive study with 177 consumers. It was found that the average of consumption was 2.69 times a year, and the main delicacies made of shell crab meat were fried shell crab meat $(n=87 \%)$, followed by shell crab meat cookie $(n=31 \%)$ and subsequently risotto, burger and pizza $(13 \%)$. It is concluded that the main products that replace the shell crab meat from cages when it is not found is fish and shrimp, and to a lesser extent meat and poultry. The price, product appearance, smell, and quality of service at the time of purchase, are the factors of the marketing mix that generate the highest dissatisfaction rates among consumers.

Keywords: Fish Trade; Crustaceans; Paraná Coast; Shell Crab.

Topic: Teoria Geral da Admistração

Reviewed anonymously in the process of blind peer.

\section{Adilson Anacleto}

Universidade Federal do Paraná, Brasil

http://lattes.cnpq.br/4935834455286413

adilson.anacleto@unespar.edu.br

Patricia Roberta Bonoli

Universidade Estadual do Paraná, Brasil

http://lattes.cnpq.br/9417408885325307

patybonoli@hotmail.com

Gabriel Alcântara da Silva

Universidade Estadual do Paraná, Brasil

http://lattes.cnpq.br/2432221971366103

galacantara@gmail.com
Received: 10/03/2016

Approved: 15/07/2016

\author{
Jose Victor Andreatta \\ Universidade Federal do Paraná, Brasil \\ http://lattes.cnpq.br/9042191103098526 \\ jvandreatta95@gmail.com \\ Glaucia Marconato \\ Universidade Estadual do Paraná, Brasil \\ http://lattes.cnpq.br/4249149557884161 \\ glaum@live.com
}

DOI: 10.6008/SPC2179-684X.2016.002.0007

Referencing this:

ANACLETO, A. BONOLI, P. R.; SILVA, G. A.; ANDREATTA, J. V.; MARCONATO, G.. Composto de marketing da carne de siri pescado com gaiolas no litoral do Paraná. Revista Brasileira de Administração Científica, v.7, n.2, p.100-109, 2016. DOI: http://doi.org/10.6008/SPC2179-684X.2016.002.0007 


\section{INTRODUÇÃO}

A pesca marítima praticada na costa paranaense, apresenta grande complexidade, sendo composta por uma grande diversidade de ambientes aquáticos, e uma grande variedade de práticas de captura que varia de acordo com as origens culturais e o local onde o pescador está inserido variando de pequenas tarrafas até grandes embarcações (ANDRIGUETTO FILHO, 2003).

A pesca no litoral do Paraná na década de 90 era realizada por mais de 10 mil pessoas, em mais de 60 vilas e bairros urbanos dos municípios de Antonina, Guaraqueçaba, Guaratuba, Matinhos, Pontal do Paraná e Paranaguá os quais sobreviviam da pesca artesanal como principal alternativa de renda (ANDRIGUETTO FILHO, 2002), sendo que segundo Anacleto et al. (2007b), eram remanescentes de comunidades caiçaras ou tradicionais, e que tinham na pesca alem da fonte de renda a principal forma de alimentação familiar.

As últimas décadas revelaram uma drástica mudança neste cenário, em especial pelo elevado esforço de pesca derivado da pratica pesqueira com o uso de grandes embarcações oriundas do Estado de São Paulo e Santa Catarina. Destaca-se que os estoques naturais de peixes e camarões que eram as espécies de maior valor comercial, não conseguiram se reproduzir a mesma velocidade das inovações tecnológicas, como barcos de motores potentes, uso de GPS para localização dos cardumes entre outras, o que conjuminou com o decréscimo da produção nesta região e por consequente a redução na renda das famílias envolvidas no setor pesqueiro (ANACLETO et al., 2007b; ANACLETO et al., 2010).

As dificuldades econômicas e a redução do poder aquisitivo, segundo Anacleto et al. (2007a), promoveu o êxodo da atividade pesqueira de centenas de famílias, sendo que atualmente, é estimado que a população tradicional de pescadores artesanais no litoral paranaense seja de aproximadamente 4.000 pessoas, de 600 famílias que vivem em 35 comunidades rurais ou urbanas localizadas mais próximas a costa.

Os pescadores residentes nestas comunidades tradicionais no litoral do Paraná diante das da nova realidade e das dificuldades de sobrevivência, iniciaram a busca por alternativas de renda pouco exploradas (ANACLETO et al., 2007b), neste contexto, surgiu no município de Paranaguá a pesca do siri com auxílio de gaiolas, visando a extração da carne do siri que é largamente usada no fabrico de diversas iguarias típicas do litoral do Paraná e largamente aceito pelos consumidores residentes e turistas na região (ANACLETO et al., 2015).

Os siris são caranguejos da família Portunidae com relevante importância ecológica e econômica nas regiões litorâneas. As espécies de siris no Brasil são representadas por um único gênero Callinectes, e duas espécies são mais capturadas no litoral do Paraná $C$. sapidus (siri guaçú) e $C$. danae (siri mirim).

Segundo Anacleto et al. (2016), atrelado a questão do turismo, a culinária regional no litoral do Paraná, também se desenvolveu, sendo que o caráter artesanal típico de produção realizado pelos pescadores nativos teve grande aceitação, e entre as muitas iguarias típicas da culinária do litoral Paranaense, destaca-se aquelas com base na carne de siri, sendo a casquinha de siri um dos pratos mais 
consumidos na região, especialmente devido ao sabor e também pela beleza da iguaria, que tradicionalmente é servido na própria carapaça do crustáceo.

Ainda segundo Anacleto et al. (2016), a captura do siri com gaiolas gera um produto de excelente qualidade, dado que o tempo de captura e preparo da iguaria é menor que o de outras espécies de captura especialmente se comparado aos grandes barcos pesqueiros que os crustáceos chegam a ficar uma semana no gelo antes da limpeza e descarne.

A maior qualidade do produto, atrelado a um baixo custo de captura promoveu que a atividade da pesca do siri com gaiolas tenha apresentado nas últimas décadas crescimento do número de pessoas praticando a modalidade e ampliando a relevância deste segmento na cadeia produtiva (ANACLETO et al., 2015).

As gaiolas utilizadas na pesca de siri são construídas pelos próprios pescadores com o uso de materiais de baixo custo e ou recicláveis, e apresentam dimensões aproximadas de $12,5 \mathrm{~cm}$ de altura, e 48 cm de diâmetro (Figura 1a), a gaiola é um tipo de armadilha sendo que após o crustáceo adentrar na mesma para se alimentar de restos de peixes iscados pelos pescadores não há possibilidade de escape, podendo permanecer vivos por muitos dias (ANACLETO et al., 2016). Segundo Anacleto et al. (2015), a captura dos crustáceos (Figura 1b), demanda tempo e muito trabalho para que o pescador consiga quantidade suficiente para o desmariscamento (Figura 1c). O caráter artesanal deste modelo de pesca leva de dois a três dias, para um pequeno volume, sendo necessários próximos de 40 siris para a extração de um quilograma de carne pronta para o uso.

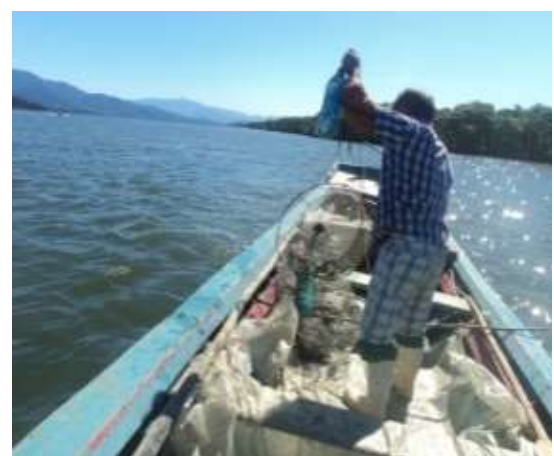

Figura 1a

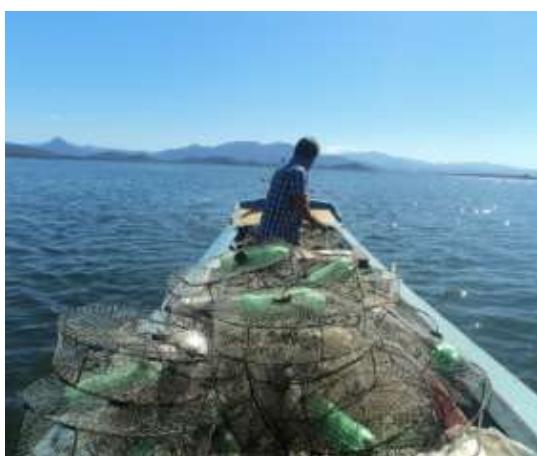

Figura $1 b$

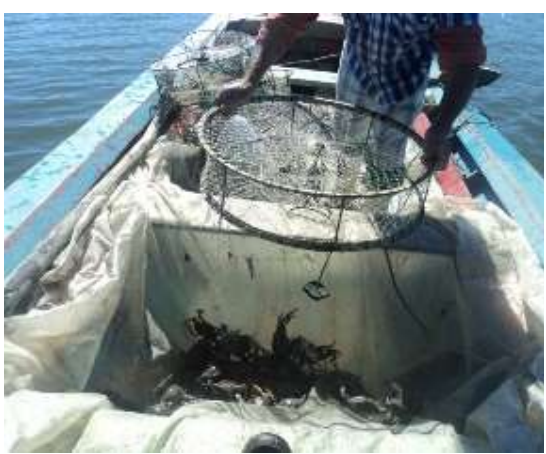

Figura $1 c$

Figura 1: Pesca do siri com gaiolas na comunidade de Tibicanga em Paranaguá Paraná, Brazil. Fotografias: Paulo Neves (2015).

A modalidade de pesca apesar do caráter extrativista, também pode ser classificada como seletiva devido ao fato dos pescadores na retirada dos crustáceos da armadilha separar os siris jovens dos siris adultos e as fêmeas que são retornados ao mar para que a reprodução não seja interrompida (ANACLETO et al., 2015).

A pesca do siri com gaiolas atualmente é a principal forma de sustento de mais de 150 famílias em toda costa paranaense, e apesar da sua relevância, e da sua grande aceitação junto ao consumidor, há uma nítida carência de informações básicas sobre o setor, especialmente sobre as preferências do consumidor deste produto (ANACLETO et al., 2015; ANACLETO et al., 2016). 
O mercado da carne do siri pescado com gaiolas, segundo Anacleto et al. (2016), ainda é embrionário quando comparado com outros frutos do mar mais tradicionais, e pouco se conhece sobre esse modelo de relação comercial, em especial sobre o composto de marketing e quais as premissas neste contexto são condicionantes ao consumo e que satisfaça os desejos e as necessidades dos consumidores e revele as suas preferências de consumo.

Segundo Kotler et al. (2012) e Churchill et al. (2012) para entender as preferencias do consumidor, é preciso entender qual o estímulo faz o cliente consumir, levando-o a decisão da compra, neste contexto, o consumidor pode ser influenciado por fatores culturais, sociais, pessoais e psicológicos, assim como por fatores situacionais (ocasionais), provenientes das condições físicas e mentais do comprador como, por exemplo, a sensação experimentada no momento da compra como o humor, tristeza e saudade.

Ainda segundo Churchill et al. (2012) o processo de compra se inicia quando o indivíduo encontra uma necessidade, podendo ser vinda de estímulos internos como os anteriormente descritos, ou externos como através de fatores criados por terceiros, por exemplo, no caso de convites para festas, ou quando surge a sensação interna, como a fome, sede, ou o contato visual com o alimento, dentre outras.

Dessa forma, a pesquisa de mercado especialmente em relação ao composto mercadológico, se faz necessária para conhecer os clientes, bem como quais são os fatores que geram a satisfação ou insatisfação no processo de compra, e desta forma atuar na redução das incertezas que ocorrem em relação a oferta de produtos tidos como embrionários no mercado (BLACKWELL et al., 2006)

O processo de compra do consumidor, segundo Churchill et al. (2012) passam por cinco etapas, sendo elas o reconhecimento da necessidade, busca de informação, avaliação das alternativas, decisão da compra e, por fim, a avaliação pós-compra.

A primeira fase sempre é a resultante dos estímulos internos ou externos que conferem ao consumidor a necessidade ou o desejo por um produto, sendo que o segundo passo consiste na busca de informação sobre o produto ou serviço que se busca adquirir; nesta fase, o consumidor toma conhecimento a respeito de diversas marcas e produtos, se utilizando de algumas fontes, sejam elas internas, como memórias do indivíduo, de membros de grupos sociais do qual o consumidor pertence, do marketing como no caso das propagandas e vendedores, sendo que é justamente nesta fase que o usuário realiza testes do produto antes da compra (CHURCHILL et al., 2012).

Tendo o conhecimento do produto, o consumidor o avalia, verificando se realmente o produto satisfaz as suas necessidades; e assim decide se irá ou não fazer a compra (KOTLER et al., 2012). A última fase é o pós-compra, que consiste em avaliar se de fato o produto atendeu ou não as expectativas, fazendo com que o consumidor forme sua opinião a respeito da marca, dos benefícios e da satisfação obtida com o produto (CHURCHILL et al., 2012).

Para fortalecer um nicho de mercado ainda no estágio embrionário, é de fundamental importância promover um diagnóstico detalhado sobre o que os compradores querem a respeito do composto de marketing, segundo Kotler et al. (2012) todas essas fases estão associadas aos 4Ps, praça, produto, preço e 
promoção, e compreende-los é fundamental para delimitar a melhor estratégia comercial no sentido de ampliar o consumo e reduzir a influência dos produtos substitutos sobre eles.

Especificamente sobre o consumo da carne de siri de gaiola, Anacleto et al. (2016) destaca como de vital importância a realização de estudos que visem o diagnóstico dos principais produtos substitutos e concorrentes da carne de siri pescado com gaiolas, bem como o entendimento das influencias do composto de marketing no comportamento do consumidor, para que se possa criar um novo posicionamento do produto no mercado, com o objetivo de elevar o nível de reconhecimento da carne de siri pelos consumidores de frutos do mar e por consequência elevar o consumo.

Assim, com o intuito de subsidiar o melhor entendimento do cenário atual da cadeia produtiva da pesca de siri com gaiolas no litoral paranaense, este estudo apresenta um diagnóstico que investiga e identifica quais fatores associados ao composto de marketing poderiam influenciar o consumo no litoral do Estado do Paraná.

\section{METODOLOGIA}

A pesquisa exploratória descritiva foi realizada a partir de entrevistas a consumidores de carne de siri pescado com gaiolas no litoral do Paraná, entre setembro a novembro de 2015 , sendo que a amostra populacional foi de 177 consumidores, que atendia as orientações de pesquisa de marketing e perfil de consumo quando a população é desconhecida (MALHOTRA, 2010).

A amostragem de acordo com o proposto por Anacleto et al. (2014) exigia que o consumidor de carne processada de siri pescado com gaiolas no litoral do Paraná deveria ter consumido pelo menos uma vez nos últimos doze meses, e que apresentasse concordância em participar da pesquisa não identificada.

O composto de marketing (preço, praça, promoção e produto) foi avaliado considerando-se o nível de satisfação do consumidor obtida pelo Modelo Kano de qualidade atrativa e obrigatória (KANO, 1984). Neste caso, o entrevistado aplicou notas aos atributos que classificava como obrigatório antes do consumo, assim como atribuiu notas de 0 a 10 posteriormente ao consumo:

a) Se a escala de expectativa de pré-requisitos antes da compra era maior que a de satisfação pós-compra, os requisitos do produto devem sofrer melhorias.

b) Se os atributos pré e pós-compra fossem equiparados, apenas evitará que o cliente fique insatisfeito (atributos neutros).

c) Se os pré-requisitos antes da compra eram menores que a satisfação pósconsumo, significa que o produto se encontrava em níveis ideais em relação ao mercado (atributos positivos) e atendia as necessidades e anseios do consumidor.

Os fatores que podem influenciar na ampliação do consumo de carne processada de siri pescado com gaiolas e a influência dos produtos substitutos ao siri foram obtidas através da categorização hierárquica que previa 5 indicações dos fatores mais relevantes. 


\section{RESULTADOS}

O estudo revelou que embora as mulheres $(n=54 \%)$ fossem a maioria numérica no consumo da carne de siri pescado com gaiolas, entre os gêneros as médias de consumo eram similares de 2,69 vezes em média ao ano. As principais iguarias na preferência dos consumidores eram a casquinha de siri $(n=87 \%)$, seguido pelo bolinho da carne de siri ( $n=31 \%)$ e posteriormente risoto, hambúrguer e pizza (13\%), condição similar também foi descrito por Anacleto et al. (2016). O consumo de peixe e camarão eram os principais produtos substitutos quando o consumidor não conseguia encontrar o que desejava, no caso o consumo da carne de siri (Tabela 1).

Tabela 1: Principais produtos substitutos quando o consumidor não conseguia encontrar a da carne de siri para o consumo ( $\mathrm{n}=177)$.

\begin{tabular}{|c|c|c|}
\hline 1 & Peixe & 273 \\
\hline 2 & Camarão & 175 \\
\hline 3 & Carne & 56 \\
\hline 4 & Aves & 32 \\
\hline 5 & Caranguejo & 31 \\
\hline 6 & Marisco & 21 \\
\hline 7 & Ostra & 17 \\
\hline
\end{tabular}

A análise do composto de marketing demonstrou que existe insatisfação generalizada dos consumidores nos fatores associados a preço, praça, promoções e produto. Observou-se maior ênfase negativa, entre os consumidores, nos atributos associados ao preço da carne de siri classificada como elevado, e acesso aos restaurantes especializados (Tabela 2).

Tabela 2: Índices de satisfação de qualidade atrativa e obrigatória do consumidor da carne de siri processada em relação ao composto de marketing - Modelo Kano (1984) ( $n=177)$.

\begin{tabular}{|c|c|c|c|c|c|c|}
\hline & & $\begin{array}{l}\text { Pré-requisito ao consumo } \\
\text { (nota média) }\end{array}$ & $\begin{array}{c}\text { Satisfação } \\
\text { pós-compra } \\
\text { (nota média) }\end{array}$ & $\begin{array}{c}\text { Índice } \\
\text { do } \\
\text { atributo }\end{array}$ & $\begin{array}{c}\text { Classificação } \\
\text { do atributo }\end{array}$ & DMS* \\
\hline \multirow[t]{3}{*}{ Preço } & Preço & 3,78 a & $3,40 \mathrm{~b}$ & $-0,38$ & Negativo & 0.28139 \\
\hline & Formas de pagamento & $3,16 \mathrm{~b}$ & $3,43 \mathrm{a}$ & $+0,70$ & Positivo & 0.26381 \\
\hline & Encontrar na quantidade & $3,54 \mathrm{a}$ & $3,54 \mathrm{a}$ & 0,00 & Nulo & 0.00000 \\
\hline \multirow[t]{4}{*}{ Praça } & Encontrar facilmente & $3,57 \mathrm{a}$ & $3,35 \mathrm{a}$ & $-0,22$ & Negativo & 0.20454 \\
\hline & Acessibilidade & 3,56 a & $3,33 b$ & $-0,23$ & Negativo & 0.17178 \\
\hline & Estacionamento & $3,62 \mathrm{a}$ & $3,23 \mathrm{~b}$ & $-0,39$ & Negativo & 0.17108 \\
\hline & Ambiente do restaurante & $4,04 \mathrm{a}$ & $3,66 \mathrm{~b}$ & $-0,38$ & Negativo & 0.17389 \\
\hline \multirow[t]{6}{*}{ Promoções } & Promoções & $4,12 \mathrm{a}$ & $4,12 \mathrm{a}$ & 0,00 & Nulo & 0.00000 \\
\hline & Aparência do produto & $4,25 \mathrm{a}$ & $4,01 \mathrm{~b}$ & $-0,24$ & Negativo & 0.16020 \\
\hline & Aparência da embalagem & $4,15 \mathrm{a}$ & $3,95 \mathrm{~b}$ & $-0,20$ & Negativo & 0.17939 \\
\hline & Frescor & $4,54 \mathrm{~b}$ & 4,07 a & $+0,57$ & Positivo & 0.16888 \\
\hline & Sabor & 4,55 a & $4,25 \mathrm{~b}$ & $-0,30$ & Negativo & 0.15295 \\
\hline & Cheiro & $4,40 \mathrm{a}$ & $4,10 \mathrm{~b}$ & $-0,30$ & Negativo & 0.16337 \\
\hline \multirow[t]{2}{*}{ Produto } & Textura & $4,07 \mathrm{a}$ & $3,99 \mathrm{a}$ & $-0,06$ & Nulo & 0.17783 \\
\hline & Qualidade do atendimento & $4,14 \mathrm{a}$ & $3,84 \mathrm{~b}$ & $-0,30$ & Negativo & 0.18393 \\
\hline
\end{tabular}

*DMS=Diferença mínima significativa pelo teste t-Student. ${ }^{a, b}$ Letras iguais não diferem estatisticamente entre si $p<0,05$.

\section{DISCUSSÃO}

A análise sobre aquilo o que pensa e deseja o consumidor de carne de siri é relevante no sentido de orientar o mercado varejista na correta oferta do produto final a mesa dos consumidores, nessa perspectiva, merece especial atenção os fatores associados ao composto de marketing. 
A forma mais comum de comercialização da carne processada nos restaurantes é a casquinha de siri, porém, para ampliar o poder de penetração do produto, é necessária uma oferta de maiores variedades de iguarias do produto, desta forma poderia atrair a atenção dos consumidores que buscam consumir variedades de pratos típicos da região.

Já com relação aos dados concernentes à promoção, estes não foram manifestos nem positivamente nem negativamente pelos entrevistados. A promoção se torna a forma com qual se promove e comunica os atributos do produto aos consumidores em potencial com vias ao consumo. Porem esta ferramenta de marketing se aplicado corretamente pode resultar em ampliação do consumo e também maior nível de satisfação do consumidor. Podem ser usados vários mecanismos, como: venda pessoal, propaganda, publicidade, promoção de vendas, merchandising, folhetaria, entre outros, porém, no litoral paranaense não são encontrados esses mecanismos de venda, em relação à divulgação exclusiva da iguaria pesquisada.

O composto de marketing é também denominado de 4 Ps (produto, praça ou ponto-de-venda, preço e promoção), os quais, de acordo com Blackwell et al. (2006), são ferramentas fundamentais tanto para a avaliação de cada fator influenciador do marketing, tanto para a implantação de novos programas relacionados à administração mercadológica como para a melhoria daqueles programas anteriormente instalados, porem destaca-se que em contexto quase que generalizado os itens atrelados ao composto de marketing receberam classificação negativa dos consumidores da carne de siri (Figura 2).

A carne de siri é ofertada em uma grande variedade de pratos e receitas como a casquinha de siri, risoto, ensopado, molho, bolinho, pastel, hambúrguer entre outros. Entretanto, dados coletados revelam insatisfação do consumidor no momento da compra em relação ao primeiro fator do composto de marketing, o produto, a saber: a aparência, embalagem, sabor, cheiro, e ainda, a qualidade no atendimento quando da aquisição do produto.

Uma das principais dificuldades descritas pelos consumidores é com relação a dificuldade de encontrar um ponto de venda no litoral paranaense que, possuam pratos específicos feitos a base de carne de siri, bem como relataram a dificuldade de encontrar nas peixarias a carne do siri fresca.

Nesse mesmo contexto, a dificuldade em encontrar a carne de siri, caracterizou-se como fator negativo pelos consumidores, ou seja, a acessibilidade ao produto devido a pouca oferta de restaurantes especializados influencia diretamente e negativamente o segundo fator do composto de marketing a "praça".

No litoral paranaense os canais de distribuição da carne de siri são insuficientes para atender satisfatoriamente a demanda, e neste contexto a barreira ao consumo pela dificuldade de encontrar facilmente o produto, atrelado as questões de tempo que as pessoas no mundo contemporâneo tem que pode ser dedicado a busca por um produto pode ser um forte limitador, alem de que o deslocamento na procura pelo produto gera um custo financeiro ao consumidor para acessar o produto devido a maiores deslocamentos, condições que podem promover a desistência do consumo.

O desestimulo ao consumo da carne de siri, pode também ser potencializado dado que segundo o estudo, a quantidade do produto ofertado não é suficiente para atender a demanda dos consumidores, o 
que acaba provocando um aumento nos preços, e segundo Kotler et al. (2012) em qualquer contexto o preço elevado é o primeiro fator na redução do consumo de um produto.

Os preços da carne de siri também foram diagnosticados por Anacleto et al. como um fator limitador ao consumo, sendo que a casquinha de siri que é a iguaria mais comercializada apresentava variação de $\mathrm{R} \$$ 11,00 até $\mathrm{R} \$ 25,00$ a unidade de 50 gramas, o que conferia o caráter de iguaria apenas degustativa dado o elevado custo.

Os consumidores em sua totalidade revelaram que diante dos elevados preços, consumiam a carne de siri mais como alternativa degustativa do processo de alimentação e não consumiam na quantidade desejada. O preço segundo Kotler et al. (2012) é um fator reduz drasticamente a experimentação de produtos em estágios embrionários, assim como reduz a frequência de compra, e dificulta o processo de fidelização do produto consumido.

O consumidor, de forma generalizada, sofre a influência de fatores internos e externos no momento do consumo, Blackwell et al. (2006) descrevem que a compra obedece ao modelo de estímulos no processamento que gera respostas e comportamento do consumidor. que possui inter-relações com todos os fatores citados, ampliando ou reduzindo a capacidade comercial de um produto, sendo o preço o fator de maior sensibilidade neste contexto. Assim o mercado varejista deve estar atento ao que se refere a questão preço, dado que preços menores conforme o reportado pelos entrevistados poderia resultar em maior consumo.

A justificativa para os elevados preços da carne de siri segundo Anacleto et al. (2016) reside em três fatores: o primeiro é a elevada aceitação do consumidor, o segundo esta a baixa oferta do produto no mercado devido ao caráter artesanal que é produzido, porem o esforço de pesca pode ser maior se as comunidades pesqueiras tivessem melhores remuneração por quilograma do produto vendido, destaca-se que as comunidades envolvidas com essa modalidade de pesca estão em condições de vulnerabilidade social e possuem renda mensal advinda desta atividade de aproximadamente $\mathrm{R} \$ 770,00$. Anacleto et al. (2015) descrevem que são necessários estudos que possam limitar a quantidade do extrativismo de siris como forma de garantir a sobrevivência dos estoques naturais das espécies, porem existem alternativas como a exploração de outras regiões pouco exploradas e o cultivo destes animais marinhos que podem em curto espaço de tempo ampliar a demanda do produto no mercado.

Porém, segundo Anacleto et al. (2016) o principal fator na majoração dos preços são os atravessadores, que devido a mobilidade e estrutura de logística promovem a aquisição destes produtos nas comunidades pesqueiras por baixo preço e quando os mesmos chegam a mesa do consumidor sofrem um acréscimo sobre o preço pago ao pescador de até $200 \%$, sendo que o pescador recebe a menor parte dentro da cadeia produtiva.

Ainda segundo os autores as relações comerciais na cadeia produtiva do siri na gaiola, revelam que em discrepância com o modelo de desenvolvimento de cadeia produtiva com gestão colaborativa, os comerciantes varejistas e atacadistas se impõem comercialmente ao pescador, e impõe preços elevados ao consumidor. $\mathrm{O}$ ambiente colaborativo deve ser adequadamente articulado, no sentido de pensar o conjunto, 
em um modelo de atuação de governança que beneficie todos os segmentos da cadeia produtiva, caso contrário o elo mais frágil no caso os pescadores localizados em comunidades socialmente vulneráveis tendem a abandonar a atividade produtiva, ou o consumidor tende a promover a substituição do produto alvo do seu desejo.

Especialmente no Litoral onde a fragilidade econômica e social dos pescadores é perceptível, nestas comunidades empobrecidas a transformação desta realidade muitas vezes é refreada pelas dificuldades naturais da atividade e também pela dificuldade de se organizar para obter melhores preços e atingir mercados mais especializados. Assim grupos sociais como estes, muitas vezes necessitam de ajuda externa, para a redução do círculo perverso que os pescadores em condições vulneráveis não possuem capacidade de investimento para acessar mercados mais especializados, e por não acessar mercados mais especializados e obter melhores remunerações da produção continuam em condições vulneráveis, conforme também descrito por Belcher et al. (2005), e enquanto isso os consumidores vivenciam a imposição do elevado preço, e ainda dificuldades de encontrar a carne de siri, que resulta em um cenário onde quanto maior for o esforço necessário para encontrar o produto desejado, mais facilmente o consumo sobre a influência dos produtos substitutos.

A influência dos produtos substitutos no caso do consumo da carne de siri ocorre no momento em que o produto pronto é ofertado ao consumidor final, e segundo Blackwell et al. (2006), o produto substituto não precisa ser igual, mas que possa satisfazer à necessidade do consumidor, sendo que e estudo revelou ainda que, quando os entrevistados não encontravam a carne de siri facilmente, os principais produtos substitutos foram o camarão, peixe e outros frutos do mar, destaca-se que os produtos substitutos sempre serão uma ameaça comercial, visto que pretende ser uma alternativa a produtos já existentes, oferecendo ao consumidor vantagens.

Os produtos buscados pelos consumidores, uma vez vencida a barreira do preço, devem apresentar qualidade, se esta condição não for atendida, os mesmos procurarão por outro produto que venha a proporcionar os mesmos objetivos, no caso o peixe e o camarão são ofertados em grande variedade em opções de pratos e possuem valor inferior ao da carne de siri. Vale ressaltar que apesar da relevância do preço no consumo, existe uma gama de consumidores que não adquire produtos apenas em função do preço, e tendem a consumi-lo independentemente do valor a ser pago, logo, o preço não será nessa classe, determinante para o consumo.

Dessa maneira, deve surgir um novo posicionamento do produto no mercado, com o objetivo de elevar o nível de reconhecimento da carne de siri pelos consumidores de frutos do mar, para que a iguaria se torne tão influente quanto os seus tradicionais produtos substitutos.

Os níveis de satisfação do consumidor diante da situação atual, demanda a necessidade urgente de um novo formato de comercialização, que seja caracterizado pelo envolvimento do comércio justo, com a inserção de atividades destinadas a desenvolver transações economicamente eficazes a todos os elos da cadeia produtiva gerando benefícios mútuos que promova ao mesmo tempo a melhoria da renda dos pescadores e redução de preço aos consumidores. 
O cenário observado revela a necessidade urgente de se implantar combinações comerciais mais harmônicas entre os segmentos, e neste contexto, a parceria comercial entre varejistas e produtores pode representar o caminho mais eficaz na redução do poder de atuação dos atravessadores da carne de siri, e na ampliação dos níveis de produção e consumo, resultando em formas mais justas de desenvolvimento sustentável destas comunidades empobrecidas e maiores benefícios junto ao consumidor final.

\section{CONSIDERAÇÕES FINAIS}

Os principais produtos que a substituem a carne de siri de gaiola quando a mesma não é encontrada é o peixe e camarão, e em menor proporção carnes e aves. 0 preço, a aparência do produto, o cheiro, a facilidade de encontrar locais para estacionamento no momento do consumo e qualidade do atendimento no momento da compra, são os fatores do composto de marketing que geram os maiores índices de insatisfação juntos aos consumidores.

O composto de marketing da carne se siri com gaiolas sofre forte influencias dos processos comerciais já estabelecidos, com o domínio comercial dos atravessadores que impõe aos consumidores elevados preços no produto final e em contexto geral influenciam o consumo no litoral do Paraná.

\section{REFERÊNCIAS}

ANACLETO, A.; BAPTISTA-METRI, C.; GONÇALVES, T. P.; CALADO, A. M.; ROSÁRIO, É. S.; PONTES, M.; NEVES, P. R.. Extrativismo do siri com gaiolas no litoral paranaense: implicações socioeconômicas. Revista SODEBRAS, v.10, p.914, 2015.

ANACLETO, A; ANDREOLLI, V. M.; MURARO, D.; ANACLETO, A. F. M.. As relações entre justiça social e desenvolvimento sustentável em remanescentes de comunidades caiçaras inseridas em ambientes florestais no litoral sul do Estado do Paraná. In: CONGRESSO INTERNACIONAL DE ADMINISTRAÇÃO. Anais. Ponta Grossa: 2007a.

ANACLETO, A.; SILVA, F. C.; PERIN, E. J.; DESCHERMAYER, S. R.. O declínio da pesca artesanal e a ostreicultura como alternativa sustentável. In: CONGRESSO INTERNACIONAL DE ADMINISTRAÇÃO. Anais. Ponta Grossa: 2007b.

ANACLETO, A.; BROETTO, B. XAVIER, F. P.; FERREIRA, K. B. S. Retail trade of caged crabmeat (Callinectes $s p$ ) on the coast of Paraná - Brazil. Business Management Dynamics, v.5, n.6, p.77-86, 2016.

ANACLETO, A.; CORDEIRO, S. A; HELERO, M. D.; SOUZA, P. M.. A mitilicultura no litoral Paranaense: desafios e oportunidades. Revista TechnoEng, v.2, p.115-128, 2010.

ANDRIGUETTO FILHO, J. M.. Sistemas técnicos de pesca no litoral do Paraná: caracterização e tipificação. In: RAYNAUT,
C.. Desenvolvimento e Meio Ambiente: em busca da interdisciplinaridade. Curitiba: EdUFPR, 2002. p.213-233

ANDRIGUETTO FILHO, J. M.. A mudança técnica e o processo de diferenciação dos sistemas de produção pesqueira do Litoral do Paraná, Brasil. Desenvolvimento e Meio Ambiente, n.8, p.43-58, 2003.

BELCHER, B.; RUIZ-PÉREZ, M.; ACHDIAWAN, R.. Global patterns and trends in the use and management of NTFPs: implications for livelihoods and conservation. World Development FAO, v.33, n.9, p.1435-1452, 2005.

BLACKWELL, R. D.; ENGEL, J. F.; MINIARD, P. W.. Consumer Behavior, South Wester, v.10, p.832, 2006.

CHURCHILL, G. A.; PETER, J. P.. Marketing: criando valor para os clientes. 3 ed. São Paulo: Saraiva, 2012

KANO, N.; SERAKU, N.; TAKAHASHI, F.; TSUJI, S.. Attractive quality and must-be quality. Journal of Japanese Society for Quality Control, Tokyo, v.14, n.2, p.39-48, 1984.

KOTLER, P.; KELLER, P.. Marketing Management. New Jersey: Prentice-Hall, 2012.

MALHOTRA, N. K.. Marketing research: An applied orientation. Upper Saddle River: Pearson, 2010. 